\title{
Economic Growth with Asset Bubbles in a Small Open Economy
}

\author{
Atsushi Motohashi \\ Development Bank of Japan Inc., Tokyo, Japan \\ Email: atsushi35@gmail.com
}

How to cite this paper: Motohashi, A. (2016) Economic Growth with Asset Bubbles in a Small Open Economy. Theoretical Economics Letters, 6, 942-961. http://dx.doi.org/10.4236/tel.2016.65097

Received: August 14, 2016

Accepted: September 17, 2016

Published: September 20, 2016

Copyright $\odot 2016$ by author and Scientific Research Publishing Inc. This work is licensed under the Creative Commons Attribution International License (CC BY 4.0).

http://creativecommons.org/licenses/by/4.0/

\begin{abstract}
This paper analyzes the characteristics of asset bubbles in a small open economy. First, we show that financial globalization relaxes the existence conditions for asset bubbles. This result implies that more countries may experience asset bubbles in a global economy. Second, we show that the effect of asset bubbles in a global economy is larger than in a closed economy. In particular, countries with high financial friction experience a high economic growth rate before a foreign bubble bursts and they are subjected to more negative influence after that. This conclusion implies that financial globalization may cause large economic movements before and after a bubble bursts.
\end{abstract}

\section{Keywords}

Asset Bubbles, Endogenous Growth, Financial Friction, Open Economy

\section{Introduction}

Asset bubbles are commonly defined as large movements in asset prices that are not explained by their fundamental value. For example, the United States economy experienced a sharp rise and drop in real-estate prices before and after 2007. This movement also occurred in the rest of the world economy around that time. Since the economic conditions or fundamentals do not change so rapidly, such a movement is considered to be asset bubble (i.e., the subprime loan-related bubble).

Some papers have already analyzed the effects of asset bubbles on the economic growth rate. The seminal papers of Samuelson [1] and Tirole [2] showed that asset bubbles crowd out investment and realize higher social welfare. Their model also showed that the appearance of asset bubbles reduces the savings flowing toward investments in a perfect financial market. 
In recent years, several papers have introduced the incompleteness of financial markets, which is called "financial friction", into the analysis. Caballero and Krishnamurthy [3], Kocherlakota [4] and Martin and Ventura [5] showed that asset bubbles have a crowding-in effect on investment and increase output in an economy with severe financial friction. Asset bubbles support the transfer of resources between those who want to invest and those who don't, because there is no effective access to finance in their approach. Yet, considering an economy with limited pledgeability, Farhi and Tirole [6] and Hirano and Yanagawa [7] showed that asset bubbles have two effects on investment: not only the crowding-in effect but also the crowding-out effect. This is because investors face a borrowing constraint in their economy, and an increase in interest rates through the appearance of asset bubbles increases the severity of the borrowing constraint.

Hirano and Yanagawa [7] showed that it is the degree of pledgeability that determines the effect of asset bubbles on investment. There is a threshold value of pledgeability below which asset bubbles are growth-enhancing and above which they are growthimpairing. They give a full characterization of the relationship between the existence conditions for asset bubbles and financial friction in a productive economy with heterogeneous investment opportunities. Subsequently, Hirano, Inaba and Yanagawa [8], using similar ideas, analyzed the optimal bailout policy in a closed economy.

These papers, however, consider a closed economy case and do not explain the effects of an asset bubble bursting in a large foreign country, like the collapse of Lehman Brothers. This paper analyzes the characteristics of asset bubbles in a small open economy to provide answers to the following two questions. First, do asset bubbles occur more frequently in a global financial market? Second, do foreign asset bubbles have a greater influence on the economic growth rate than internal asset bubbles do?

We extend the models and ideas of Hirano and Yanagawa [7] and Hirano, Inaba and Yanagawa [8] to answer these questions. This paper has two main contributions. First, we show that financial globalization relaxes the existence condition for asset bubbles in small countries. That is because small countries with financial friction have some residual assets that are not allocated to good investment opportunities. Thus, foreign bubbly assets become an attractive investment opportunity for these assets. This result implies that more countries may experience asset bubbles in a global economy. Second, we show that financial globalization enhances the economic growth rate in small countries with high financial friction before the bursting of a foreign asset bubble and they are subject to much more negative influence after that. That is because countries with high financial friction have many more residual assets which they invest in foreign bubbly assets than countries with low financial friction do. As a result, they gain a lot of investment return from foreign bubbly assets and are able to invest such return on good investment opportunities. This creates a high economic growth rate before the bubble bursts, but afterward they experience a low economic growth rate as a result of the loss of assets. We also show that the effect of asset bubbles in a global economy is larger than it is in a closed economy, because the investment return from foreign bubbly assets is higher than that from internal bubbly assets. This conclusion implies that financial globalization has the potential to cause large economic movements in the world economy. 
This paper is organized as follows. In Section 2, we introduce the basic setup of the model. In Section 3, we define a competitive equilibrium based on the setup, and derive the economic growth rate in a small open economy. In Section 4, we analyze the effects of financial globalization on the existence conditions for asset bubbles and the economic growth rate. Finally, in Section 5, we summarize the main insights and present some ideas for future research.

\section{The Model}

\subsection{Background of the Model}

The latest asset bubble has one typical characteristic: financial investors outside the United States hold bubble assets in the United States through securitized products. The development of securitization technologies makes it easy for US financial institutions to sell various securitized products to buyers all over the world. We call this phenomenon "financial globalization". As a result of this financial globalization investors in many parts of the world could indirectly hold foreign assets in the United States whose prices exceed their fundamental values. Thus, the emerging and bursting asset bubbles in the United States (a big country) could affect the economic growth in the rest of the world (small countries).

Such bubble assets which are held by investors in small countries are called "foreign bubbly assets", and asset bubbles caused by them in small countries are called "foreign asset bubbles". Conversely, bubble assets in a closed economy, which are generated and held in small countries, are called "internal bubbly assets", and asset bubbles caused by them are called "internal asset bubbles". To analyze asset bubbles in a general equilibrium framework, they are introduced into the model as a type of security, and foreign and internal bubbly assets correspond to the portion exceeding the fundamental value.

We construct a model to analyze the effects of asset bubbles in a small open economy by extending the model of Hirano and Yanagawa [7]. In our model the international interest rate corresponds to the return from investment in foreign bubbly assets and is exogenously given. This is called "the foreign investment return".

\subsection{The Structure of the Model}

A typical entrepreneur model with financial friction in a discrete-time economy is considered. There is no population growth, and the economy has one homogeneous good and a continuum of entrepreneurs.

A typical entrepreneur has the expected discounted utility function

$$
E_{0}\left[\sum_{t=0}^{\infty} \beta^{t} \log c_{t}^{i}\right]
$$

where $i$ is the index for each entrepreneur, and $c_{t}^{i}$ is his consumption at date $t$. The parameter $\beta \in(0,1)$ is the subjective discount factor, and $E_{0}[x]$ is the expected value of $x$ conditional on information at time 0 . A log-linear utility function is adopted to analyze the effects of the appearance of foreign investment opportunities on internal projects.

Each entrepreneur encounters two types of investment project every period: high 
productive investment projects (H-projects) and low productive investment projects (L-projects). At the beginning of every period, each entrepreneur encounters H-projects (L-projects) with probability $p$ (probability $1-p$ ) which is exogenous and independent across entrepreneurs and constant over time. As a result, the productivity of each entrepreneur's portfolio changes over time. An entrepreneur with $\mathrm{H}$-projects (Lprojects) is called an "H-entrepreneur" ("L-entrepreneur"). The index $i$ indicates the type of entrepreneur: $i=\{H, L\}$. The investment technologies (output from each investment project) is expressed by the production function

$$
y_{t+1}^{i}=\alpha_{t}^{i} z_{t}^{i}
$$

where $z_{t}^{i}(\geq 0)$ is the investment at datet and $y_{t+1}^{i}$ is the output at date $t+1$. Owing to the linearity of the production function, $\alpha_{t}^{i}$ corresponds the marginal productivity of investments at date $t$. Since $\mathrm{H}$-projects give a high return to an $\mathrm{H}$-entrepreneur, $\alpha_{t}^{i}$ satisfies $\alpha_{t}^{H}>\alpha_{t}^{L}$. In addition, we assume $\alpha_{t}^{i}=\alpha^{i}$ for simplicity.

Each entrepreneur faces the following flow of funds constraint every period:

$$
c_{t}^{i}+z_{t}^{i}+w_{t}^{i}=\left(y_{t}^{i}+r_{t-1}^{w} w_{t-1}^{i}-r_{t-1}^{w} b_{t-1}^{i}\right)+b_{t}^{i}
$$

where $w_{t}^{i}$ is the amount spent on purchasing foreign bubbly assets, $b_{t}^{i}$ is the amount of borrowing at date $t$, and $r_{t}^{w}$ is the foreign investment return (the international interest rate) at date $t$. The left hand side of (3) is the gross expenditure, and the financing of this is expressed by the right hand side. Then the net worth of the entrepreneur is defined to be $e_{t}^{i} \equiv y_{t}^{i}+r_{t-1}^{w} w_{t-1}^{i}-r_{t-1}^{w} b_{t-1}^{i}$ to express its economic implications.

The foreign investment return is assumed to equal or even exceed the marginal productivity of L-projects, because large countries have advanced financial tools and an effective manufacturing sector. Offering a new opportunity for asset management to the entrepreneur in small counties, the interest rate in small counties converges to the foreign investment return $r_{t}^{w}$. In addition to that, to exclude the case where the entrepreneur manages their all assets as foreign bubbly assets, we assume that the investment return doesn't exceed the marginal productivity of H-projects. Thus, the foreign investment return $r_{t}^{w}$ satisfies the conditions

$$
\alpha_{t}^{L} \leq r_{t}^{w} \leq \alpha_{t}^{H}, r_{t}^{C} \leq r_{t}^{w} \text { and } r_{t}^{C N} \leq r_{t}^{w}
$$

where $C$ is the index for a closed economy and $N$ is the index for an economy with non-bubble assets. The rates $r_{t}^{C}$ and $r_{t}^{C N}$, therefore, correspond to the equilibrium interest rates in closed economies with and without bubbly assets, respectively. We also assume $r_{t}^{w}=r^{w}$ for simplicity ${ }^{1}$.

Each entrepreneur also faces borrowing constraints. He can pledge at most a fraction of future returns from investment to creditors due to financial friction in the economy. Thus, the borrowing constraint is expressed as

$$
r^{w} b_{t}^{i} \leq \theta\left(\alpha^{i} z_{t}^{i}+r^{w} w_{t}^{i}\right)
$$

\footnotetext{
${ }^{1}$ The case where $r_{t}^{w}>\alpha_{t}^{H}$ corresponds to the case that countries are heavily dependent on asset management. One representative example of this is Iceland before the fall of Lehman Brothers. Such countries realize high economic growth rate before asset bubbles burst, but lose all assets after that.
} 
where the parameter $\theta \in[0,1]$ corresponds to the degree of imperfection of the financial market. Tirole [9] gives the foundations of this setting. We can easily provide a micro-foundation for $\theta$ by applying the ideas of Tirole [9] to this model (see Appendix A).

Finally, the probability of the bursting of foreign asset bubbles is considered. When it is defined as $\gamma(0 \leq \gamma<1)$, the required return of foreign bubbly assets should be $w_{t+1}^{i}=r^{w}[1 /(1-\gamma)] w_{t}^{i}$. To simplify our analysis, we assume an economy where the entrepreneur believes the rating of assets (that is wrong ex post facto) and he never realizes the real risks of assets until asset bubbles burst (therefore, $\gamma=0)^{2}$. This assumption is consistent with observed facts. For example, Brunnermeier et al. [10] point out the problems with regard to the rating of securities. Securities become too complicated to figure out the risks clearly and their ratings do not reflect the real risks of the assets ${ }^{3}$.

\section{Market Equilibrium}

The previous section provides a basic setup with which to construct a model to analyze the effects of asset bubbles in a small open economy. In this section, we define the competitive equilibrium and derive the economic growth rate in a small open economy. Then we do the same for a closed economy. Comparing these results, we are able to clarify the difference between the existence conditions for asset bubble and the additional effects of foreign bubbly assets on the economic growth rate as a result of financial globalization.

\subsection{Competitive Equilibrium in a Small Open Economy}

In this subsection, we provide a competitive equilibrium with foreign bubbly assets in a small open economy. The competitive equilibrium is defined as sequences of foreign investment returns $\left\{r_{t}^{w}=r^{w}\right\}_{t=0}^{\infty}$ and other economic variables $\left\{c_{t}^{i}, b_{t}^{i}, z_{t}^{i}, y_{t+1}^{i}, C_{t}^{H}, C_{t}^{L}, B_{t}^{H}, B_{t}^{L}, W_{t}^{H}, W_{t}^{L}, Y_{t}^{H}\right\}_{t=0}^{\infty}$ that satisfy the following conditions.

1. Each entrepreneur maximizes their utility under some constraints:

$$
\begin{gathered}
\max _{c_{t}^{i}} E_{0}\left[\sum_{t=0}^{\infty} \beta^{t} \log c_{t}^{i}\right], \\
\text { subject to } c_{t}^{i}+z_{t}^{i}+w_{t}^{i}=e_{t}^{i}+b_{t}^{i}, r^{w} b_{t}^{i} \leq \theta \alpha_{t}^{i} z_{t}^{i}+\theta r^{w} w_{t}^{i} \text { and } w_{t}^{i} \geq 0,
\end{gathered}
$$

2. The market clearing conditions are

$$
\begin{gathered}
C_{t}^{H}+C_{t}^{L}+Z_{t}^{H}+Z_{t}^{L}+W_{t}^{H}+W_{t}^{L}=Y_{t}^{H}+r^{w} W_{t-1}^{L}, \\
B_{t}^{H}+B_{t}^{L}=0,
\end{gathered}
$$

where the aggregate consumption, investment, output, borrowing and purchasing of foreign bubbly assets of each type of entrepreneur at date $t$ are, respectively, designated as

${ }^{2}$ Our main results do not change even when $\gamma \neq 0$ is assumed.

${ }^{3}$ Brokerage houses securitize mortgages and create mortgage-backed securities (MBS) and collateralized debt obligations (CDOs) and so on. They repeat securitization to produce high-rating (i.e., AAA) securities. Such repeated securitization, however, obscures the risks of assets. In addition, credit-rating agencies have a conflict of interest in making severe ratings cuts, because they earn revenue from brokerage houses who are sellers of such assets. This fact also makes it difficult for credit-rating agencies to assign the right grades to securitized products. 
follows: $\sum_{i \in H_{t}} c_{t}^{i} \equiv C_{t}^{H}, \quad \sum_{i \in L_{t}} c_{t}^{i} \equiv C_{t}^{L}, \quad \sum_{i \in H_{t}} z_{t}^{i} \equiv Z_{t}^{H}, \quad \sum_{i \in L_{t}} z_{t}^{i} \equiv Z_{t}^{L}, \quad \sum_{i \in H_{t}} y_{t}^{i} \equiv Y_{t}^{H}$, $\sum_{i \in L_{t}} y_{t}^{i} \equiv Y_{t}^{L}, \quad \sum_{i \in H_{t}} b_{t}^{i} \equiv B_{t}^{H}, \quad \sum_{i \in L_{t}} b_{t}^{i} \equiv B_{t}^{L}, \quad \sum_{i \in H_{t}} w_{t}^{i} \equiv W_{t}^{H}, \quad \sum_{i \in L_{t}} w_{t}^{i} \equiv W_{t}^{L}$.

It is well known that an entrepreneur with the log-linear utility function (1) consumes a fraction $1-\beta$ of the net worth every period:

$$
c_{t}^{i}=(1-\beta) e_{t}^{i} \text {. }
$$

\subsubsection{The Investment Function}

Next we consider the investment function of each entrepreneur to derive the economic growth rate in the equilibrium. An L-entrepreneur prioritizes lending his assets to an $\mathrm{H}$-entrepreneur over investing in L-projects, because the foreign investment return (lending interest rate) equals or even exceeds the marginal productivity of L-projects. An L-entrepreneur lends his assets to $\mathrm{H}$-entrepreneurs up to the limit of the borrowing constraint, and then buys the foreign bubbly assets using residual assets ${ }^{4}$. An L-entrepreneur, therefore, doesn't invest in internal projects in his own country. However, an $\mathrm{H}$-entrepreneur borrows assets from L-entrepreneurs and invests all his assets in $\mathrm{H}$-projects, because the marginal productivity of $\mathrm{H}$-projects exceeds the foreign investment return. As a result, $\mathrm{H}$-entrepreneurs are the only entrepreneurs who invest in internal projects in small countries. Combining the budget constraint and the borrowing constraint (7) and (8), the investment function of an $\mathrm{H}$-entrepreneur is

$$
z_{t}^{H}=\frac{\beta e_{t}^{H}}{1-\frac{\theta \alpha^{H}}{r^{w}}}=\beta e_{t}^{H} \mu\left(r^{w}, \theta\right),
$$

where $\mu\left(r^{w}, \theta\right)$ is defined as $1 /\left[1-\left(\frac{\theta \alpha^{H}}{r^{w}}\right)\right]$. Since $\beta e_{t}^{H}$ represents the savings account of an H-entrepreneur, the function $\mu\left(r^{w}, \theta\right)$ corresponds to his multiple of investments to owed capital. We call it the "leverage factor of investments". Since only $\mathrm{H}$-entrepreneurs invest in internal projects, the investment function of the country is expressed as the aggregate investment of $\mathrm{H}$-entrepreneurs:

$$
Z_{t}^{H}=\frac{\beta E_{t}^{H}}{1-\frac{\theta \alpha^{H}}{r^{w}}}=\beta E_{t}^{H} \mu\left(r^{w}, \theta\right) .
$$

The investment function depends on the net worth of H-entrepreneurs at date $t$. As mentioned before, $\mathrm{H}$-entrepreneurs at date $t$ arise from proportions $p$ of $\mathrm{L}$ and $\mathrm{H}$-entrepreneurs at date $t-1$. After borrowing and lending, each entrepreneur only buys foreign bubbly assets or invests in $\mathrm{H}$-projects, respectively. Thus, considering the market clearing condition (9), the net worth of $\mathrm{H}$-entrepreneurs at date $t$ is given by

$$
E_{t}^{H}=p\left(Y_{t}^{H}-r^{w} B_{t-1}^{H}\right)+p\left(r^{w} W_{t-1}^{L}-r^{w} B_{t-1}^{L}\right)=p\left(Y_{t}^{H}+r^{w} W_{t-1}^{L}\right) .
$$

As a result, the investment function (12) is replaced by

${ }^{4} \mathrm{By}$ introducing some slight cost to buy foreign bubbly assets, an L-entrepreneur has an incentive to set the price of lending to $\mathrm{H}$-entrepreneurs above that of buying foreign bubbly assets. 


$$
Z_{t}^{H}=\frac{\beta p\left(Y_{t}^{H}+r^{w} W_{t-1}^{L}\right)}{1-\frac{\theta \alpha^{H}}{r^{w}}}=\beta p\left(Y_{t}^{H}+r^{w} W_{t-1}^{L}\right) \mu\left(r^{w}, \theta\right) .
$$

\subsubsection{The Economic Growth Rate}

Finally, we consider the economic growth rate in a small open economy. The gross income of the country is

$$
Y_{t+1}+r^{w} W_{t}=\alpha_{t}^{H} Z_{t}^{H}+r^{w} W_{t} .
$$

In order to characterize the economic growth rate, we define the relative size of foreign bubbly assets $\left(k_{t}\right)$ and the growth rate of aggregate wealth $\left(g_{t}\right)$, respectively, as follows

$$
\begin{gathered}
k_{t}=\frac{W_{t}}{\beta\left(Y_{t}^{H}+r^{w} W_{t-1}^{L}\right)}, \\
g_{t}=\frac{Y_{t+1}+r^{w} W_{t}}{Y_{t}+r^{w} W_{t-1}} .
\end{gathered}
$$

From Equation (14) and these definitions, the growth rate of aggregate wealth (17) can be expressed as

$$
g_{t}=\alpha^{H} \frac{\beta p}{1-\frac{\theta \alpha^{H}}{r^{w}}}+r^{w} \beta k_{t} .
$$

This equation implies important characteristics of foreign asset bubbles in a small open economy. The first term of the equation corresponds to the leverage factor of investments, and the second term corresponds to the return from investments in foreign bubbly assets. As is clear from this equation, financial globalization, which lets the internal interest rate increase to the foreign investment return, reduces the leverage factor of investments and has a negative effect on the economic growth rate. On the other hand, the emergence of foreign asset bubbles offers the entrepreneur a new investment opportunity and brings him foreign investment income. Since he invests the income on internal projects, capital accumulation is stimulated in the country. These two effects will play a key role when we analyze the effects of foreign bubbly assets in a small open economy.

Combining Equations (8), (10) and the definition of $k_{t}$, the market clearing condition is expressed as follows 5 ,

$$
\frac{\beta p}{1-\frac{\theta \alpha^{H}}{r^{w}}}+\beta k_{t}=\beta .
$$

Furthermore, from an elementary calculation of the investment function (14), it is clear that the growth rate of the total output $\left(g_{t}^{*} \equiv Y_{t+1} / Y_{t}=Z_{t+1}^{H} / Z_{t}^{H}\right)$ equals the growth rate of aggregate wealth $\left(g_{t}\right)$. Thus, we call this quantity "the economic growth rate". ${ }^{5}$ From elementary calculation, we can derive the relative size of foreign bubbly assets in equilibrium as follows: $k_{t}=\left[r^{w}(1-p)-\theta \alpha^{H}\right] /\left[r^{w}-\theta \alpha^{H}\right]$. We can interpret this equation as a general form that expresses the relative size of residual assets invested on alternative investment opportunity. This point is valid when we consider closed economy cases in Section 3.2. 
Combining the Equation (18) with the market clearing condition (19), we obtain the following theorem.

Theorem 1. The economic growth rate in a small open economy is expressed as a function of the degree of imperfection of the financial market and the foreign investment return of the country. That is, it is given by

$$
g_{t}\left(r^{w}, \theta\right)=g_{t}^{*}=\beta p\left(\alpha^{H}-r^{w}\right) \mu\left(r^{w}, \theta\right)+\beta r^{w}
$$

The first term of Equation (20) depends on the leverage factor of investments and difference between the marginal investment returns, and the second term corresponds to the return from foreign bubbly assets. Thus, we call these terms "extended investment leverage" and "foreign investment income", respectively. This second effect is a unique characteristic of a small open economy. If the economy has high financial friction (low $\theta$ ) or low internal investment opportunity (low $p$ ), the entrepreneur has a lot of residual assets. Investing the majority of residual assets on foreign bubbly assets, the country is more influenced by the emergence and bursting of foreign asset bubbles. Theorem 1 implies that countries with relatively high financial friction tend to become creditor nations, and their economic growth rates are maintained at a high level before asset bubbles in a large foreign country burst. These implications obtained from this model fit the observed facts. The following Figure 1 and Figure 2 show the economic growth rates and the balance of current account and GDP ratio in several countries before and after the collapse of Lehman Brothers.

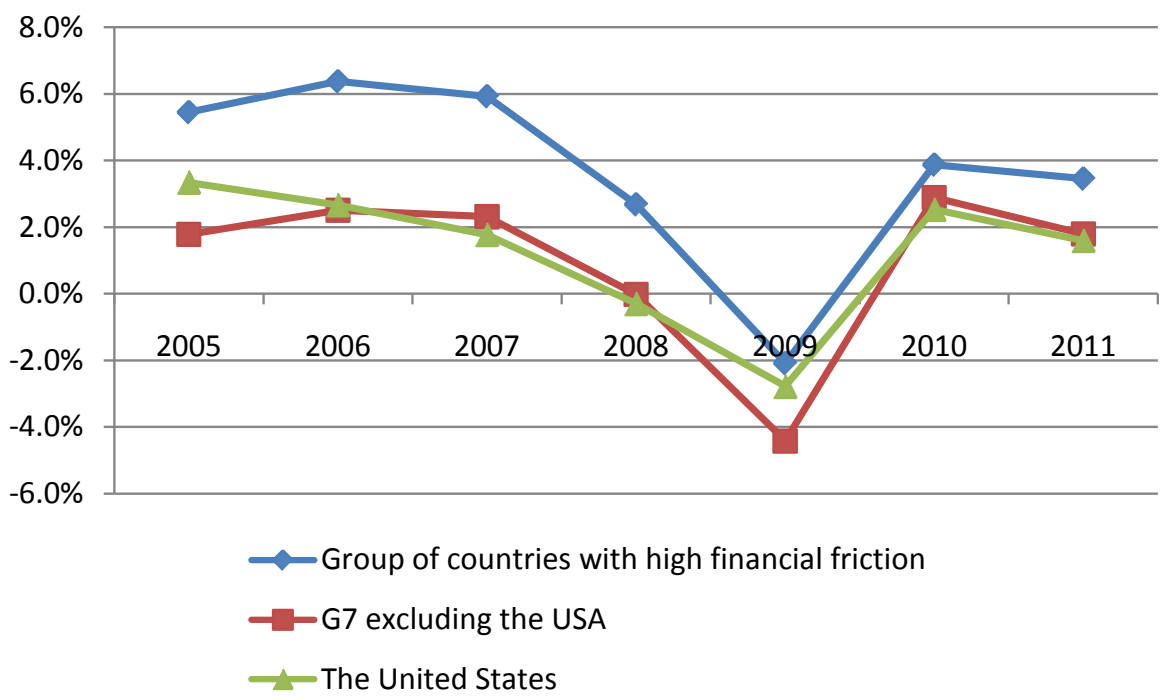

Figure 1. Economic growth rates (data from "World Development Indicators" database) ${ }^{6}$.

${ }^{6} \mathrm{We}$ chose following countries to form the "group of countries with high financial friction": Algeria, Belgium, China, Croatia, Denmark, Hong Kong, Kuwait, Macedonia, Norway, Poland, Singapore, Slovak Republic, Sweden, and Trinidad and Tobago. These countries are rated level 4 in the report of The World Bank [11] "Depth of credit information index (level 0-6 (low to high))". We excluded countries in which the prevalence of undernourishment is above $10 \%$ from the group, because an entrepreneur in such countries prefers consumption to buying foreign bubbly assets. Countries with level 3 and under are also excluded because their prevalence of undernourishment is over 15\% (Section "2.20 Nutrition: Prevalence of undernourishment" in the report presented by The World Bank [11]). 


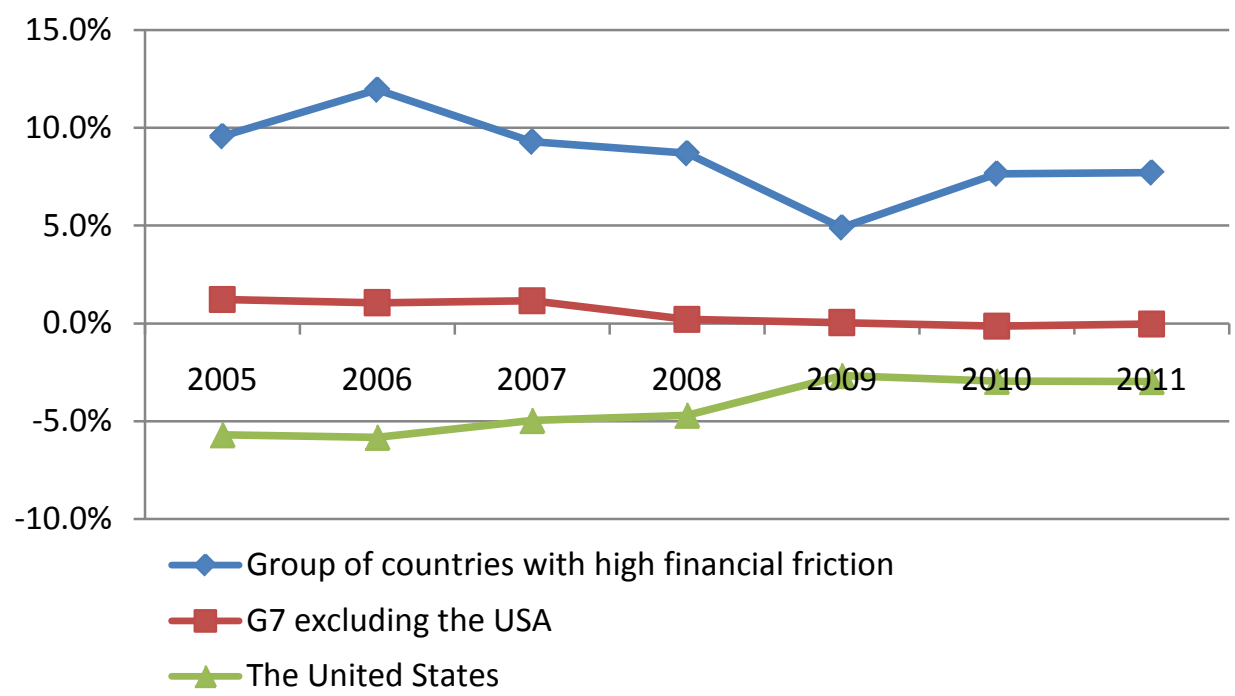

Figure 2. The balance of current account and GDP ratio (data from "World Development Indicators" database).

\subsection{Competitive Equilibrium in a Closed Economy}

In this subsection, we derive the equilibrium interest rate and the economic growth rate in a closed economy. These cases have been already derived in Hirano and Yanagawa [7], but we show that the same conclusions are easily derived from Theorem 1. An Lentrepreneur invests in foreign bubbly assets in an open economy; on the other hand, in a closed economy, he invests in internal bubbly assets. If there is no bubbly asset in a closed economy, he invests residual assets on L-projects. First, we consider the case with internal bubbly assets. The case with no bubbly assets is considered after that.

\subsubsection{Internal Bubble Equilibrium}

As mentioned above, if internal bubbles emerge in a closed economy, an entrepreneur has an opportunity to buy internal bubbly assets instead of foreign bubbly assets. The internal bubble equilibrium, therefore, is defined by introducing a domestic interest rate instead of the foreign investment return. Based on the same idea as Theorem1, the economic growth rate is expressed as

$$
g_{t}^{C}=g_{t}^{C^{*}}=\beta p\left(\alpha^{H}-r_{t}^{C}\right) \mu\left(r_{t}^{C}, \theta\right)+\beta r_{t}^{C},
$$

where $C$ is the index for a closed economy, and $r_{t}^{C}$ is the domestic interest rate. In a closed economy, the domestic interest rate should be equal to the economic growth rate. This is a necessary and sufficient condition to sustain stable internal asset bubbles in a closed economy (see Appendix B). Thus, the equilibrium interest rate and the economic growth rate in an internal bubble economy are

$$
g_{t}^{C}=g_{t}^{C^{*}}=r_{t}^{C}=\alpha^{H} \frac{(1-\beta) \theta+p \beta}{1-\beta+p \beta} .
$$

\subsubsection{No-Bubble Equilibrium}

In an economy with no bubble assets, an L-entrepreneur invests his residual assets in 
L-projects. He, however, is able to lend all his assets to an H-entrepreneur, if the level of financial friction is not so severe. Thus, the equilibrium economic growth rate depends on the conditions

$$
\left(r_{t}^{C N}-\alpha^{L}\right) k_{t}^{C N}=0,
$$

where $k_{t}^{C N}=\frac{r_{t}^{C N}(1-p)-\theta \alpha^{H}}{r_{t}^{C N}-\theta \alpha^{H}} \geq 0, r_{t}^{C N}-\alpha^{L} \geq 0$.

Here, $k_{t}^{C N}$ corresponds to the relative size of investment on L-projects. If borrowing constraints bite, L-entrepreneurs invest their residual assets in L-projects $\left(k_{t}^{C N}>0\right)$. Since the marginal return from L-projects is $\alpha^{L}$, the domestic interest rate should be equal to $\alpha^{L}$ in the equilibrium. On the other hand, if borrowing constraints do not bite, an L-entrepreneur lends his all assets to $\mathrm{H}$-entrepreneur $\left(k_{t}^{C N}=0\right)$. Thus, the domestic interest rate is determined by the supply and demand of assets in a lending and borrowing market. As a result, combining these conditions and the idea of theorem 1, we have

$$
\begin{gathered}
g_{t}^{C N}=g_{t}^{C N^{*}}= \begin{cases}\beta\left(\alpha^{H}-\alpha^{L}\right) p \mu\left(\alpha^{L}, \theta\right)+\beta \alpha^{L}, & \text { if } 0 \leq \theta<(1-p) \frac{\alpha^{L}}{\alpha^{H}}, \\
\beta \alpha^{H}, & \text { if }(1-p) \frac{\alpha^{L}}{\alpha^{H}} \leq \theta<1-p, \\
\beta \alpha^{H}, & \text { if } 1-p \leq \theta,\end{cases} \\
r_{t}^{C N}= \begin{cases}\alpha^{L}, & \text { if } 0 \leq \theta<(1-p) \frac{\alpha^{L}}{\alpha^{H}}, \\
\frac{\theta \alpha^{H}}{(1-p)}, & \text { if }(1-p) \frac{\alpha^{L}}{\alpha^{H}} \leq \theta<1-p, \\
\alpha^{H}, & \text { if } 1-p \leq \theta,\end{cases}
\end{gathered}
$$

where $N$ is an index indicating a no-bubble economy $y^{7}$.

\section{Characteristics of Asset Bubbles in a Small Open Economy}

\subsection{Existence Conditions for Asset Bubbles}

In this subsection, we analyze the effects of financial globalization on the existence conditions for asset bubbles. We provide an answer to the question of whether asset bubbles occur more frequently in a global economy. Comparing the range of the existence conditions in a small open economy with that in a closed economy, we can clarify the effects of globalization. First, we derive the existence conditions in a small open economy, and then a closed economy is considered.

In a small open economy, the following conditions need to be satisfied to sustain foreign bubbly assets:

$$
k_{t}=\frac{r^{w}(1-p)-\theta \alpha^{H}}{r^{w}-\theta \alpha^{H}}>0
$$

${ }^{7}$ See Hirano and Yanagawa [7] for the details of the derivation. 


$$
\begin{gathered}
\alpha^{L} \leq r^{w} \leq \alpha^{H}, \\
r_{t}^{C N} \leq r^{w} .
\end{gathered}
$$

Equation (26) corresponds to the condition that the entrepreneur invests in foreign bubbly assets in the equilibrium. Equation (27) corresponds to the condition that the foreign investment return equals or even exceeds the equilibrium interest rate and does not exceed the marginal productivity of H-projects. Equation (28) is a condition specific to a small open economy, which we mentioned before. As a result, we have the following existence conditions for foreign bubbly assets:

$$
\left\{\begin{array}{l}
\alpha^{L} \leq r^{w} \leq \alpha^{H}, \quad \text { if } 0 \leq \theta<(1-p) \frac{\alpha^{L}}{\alpha^{H}}, \\
\frac{\theta \alpha^{H}}{(1-p)} \leq r^{w} \leq \alpha^{H}, \quad \text { if }(1-p) \frac{\alpha^{L}}{\alpha^{H}} \leq \theta \leq 1-p .
\end{array}\right.
$$

On the other hand, the closed economy case is derived using the same ideas as the small open economy case. Taking $r^{w}=r_{t}^{C}$ in equations (26) and (27), we have following conditions:

$$
\begin{gathered}
r_{t}^{C}=\alpha^{H} \frac{(1-\beta) \theta+p \beta}{1-\beta+p \beta} \\
\text { if } \operatorname{Max}\left[\frac{\alpha^{L}-\beta\left[\alpha^{L}+\left(\alpha^{H}-\alpha^{L}\right) p\right]}{\alpha^{H}(1-\beta)}, 0\right] \equiv \bar{\theta} \leq \theta<\beta(1-p) .
\end{gathered}
$$

It is clear from Figure 3 that the range of (29) is larger than that of (30). As a result, we have the following theorem.

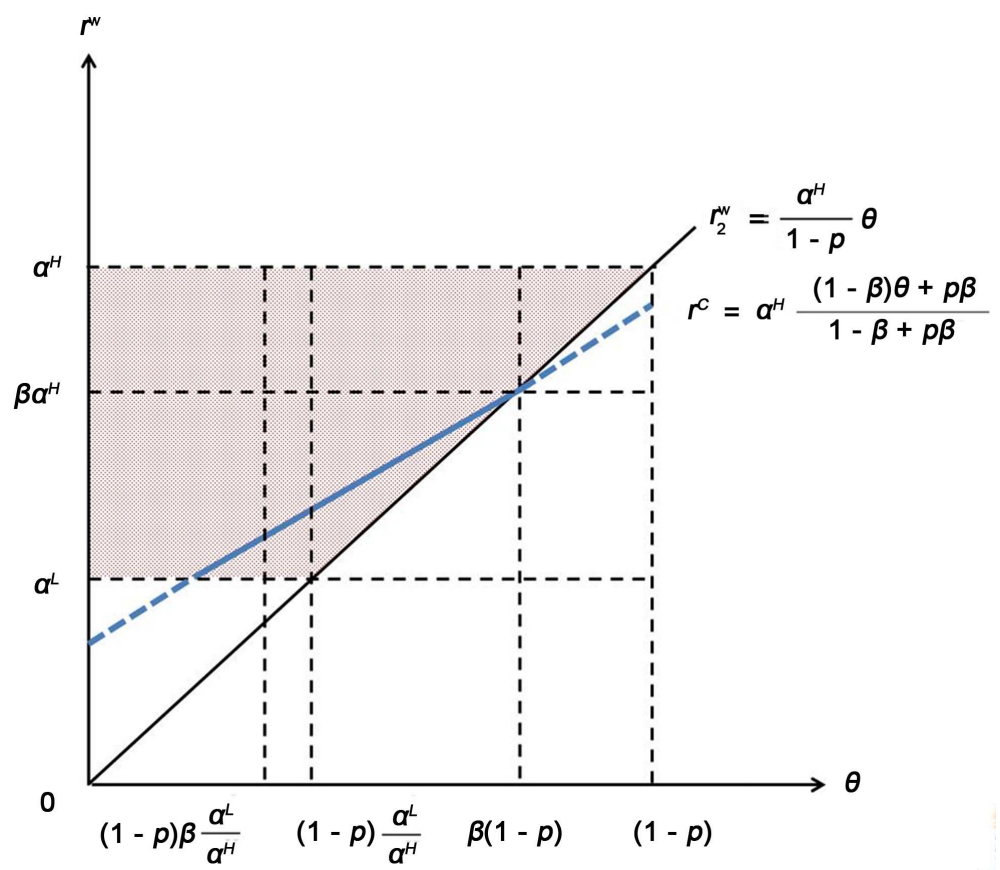

Figure 3. The existence conditions for asset bubbles. 
Theorem 2. Financial globalization relaxes the existence conditions for asset bubbles.

Here, we discuss the reason why asset bubbles may emerge in countries with higher financial friction. L-entrepreneurs have a lot of residual assets in both closed and open economies. In a closed economy, however, the amount of internal bubbly assets is limited. As a result, the expected return from internal bubbly assets dips below the marginal productivity of investments in L-projects. Thus, there is the floor $(\underline{\theta})$ in a closed economy. On the other hand, in a small open economy, L-entrepreneurs have the option to invest in foreign bubbly assets. Thus, as far as its L-entrepreneurs have residual assets, a country has the possibility to become an asset bubble economy.

\subsection{Asset Bubbles and Economic Growth}

In this subsection, we analyze the effects of financial globalization on the economic growth rate. We provide an answer to the question of whether foreign asset bubbles have a greater influence on the economic growth rate than internal asset bubbles.

\subsubsection{Comparison with a No-Bubble Economy}

First, to understand the effects of financial globalization, we compare the economic growth rate in a foreign asset bubble equilibrium with that in a no-bubble economy. Financial globalization turns the interest rate in a small country into the foreign investment return. As mentioned before, that increase of the equilibrium interest rate has two effects on the economic growth rate in the country. First of all, it improves the investment return of L-entrepreneurs. On the other hand, it decreases the leverage factor of investments, because budget constraints become tighter as a result of the upturn in interest rate.

Combining equations (20) and (24), we derive the interest rates that make economic growth rates equal in both economies (see Appendix $\mathrm{C}$ ):

$$
\begin{cases}r_{1}^{w}=\alpha^{L}, r_{2}^{w}=\frac{\theta \alpha^{H}\left[\alpha^{L}(1-p)+\alpha^{H}(p-\theta)\right]}{(1-p)\left(\alpha^{L}-\theta \alpha^{H)},\right.} & \text { if } 0 \leq \theta<(1-p) \frac{\alpha^{L}}{\alpha^{H}}, \\ r_{3}^{w}=\frac{\alpha^{H}}{1-p} \theta, & \text { if }(1-p) \frac{\alpha^{L}}{\alpha^{H}} \leq \theta \leq 1-p\end{cases}
$$

where $r_{1}^{w}$ and $r_{3}^{w}$ are the equilibrium interest rates in a closed economy, and $r_{2}^{w}$, therefore, corresponds to the interest rate at which the above two effects cancel each other. As a result, we have the following theorem.

Theorem 3. Financial globalization enhances the economic growth rate in small countries with high financial friction, if the foreign investment return satisfies $\operatorname{Max}\left[r_{1}^{w}, r_{2}^{w}\right]<r^{w} \leq \alpha^{H}$. On the other hand, it produces the opposite outcome in small countries with low financial friction, if the foreign investment return satisfies $r_{3}^{w}<r^{w} \leq \alpha^{H}$.

Theorem 3 shows the following things. In a country with an advanced financial market $\left((1-p) \alpha^{L} / \alpha^{H} \leq \theta \leq 1-p\right)$, the economic growth rate equals that in a perfect financial market, because anH-entrepreneur isable to borrow sufficient assets. As a result, the upturn of the interest rate has a negative influence on the economic growth rate 
through a tightening of the borrowing constraint. However, in a country with a nonadvanced financial market $\left(0 \leq \theta<(1-p) \alpha^{L} / \alpha^{H}\right)$, the upturn of the interest rate has a positive influence on the economic growth rate. That is because the borrowing constraint is too tight for an L-entrepreneur to lend all his assets to H-entrepreneurs and invests a lot of residual assets in L-projects in the economy. Financial globalization offers him the opportunity to invest in foreign bubbly assets that bring a higher return to an L-entrepreneur than L-projects. Figure 4 illustrates these relationships between the economic growth rate and the foreign investment return in countries with various levels of financial friction in a small open economy.

\subsubsection{Comparison with an Internal Bubble Economy}

Next, we compare the economic growth rate in a foreign asset bubble equilibrium with that in an internal asset bubble equilibrium. Because foreign bubbly assets offer a higher investment return to an L-entrepreneur than internal bubbly assets do, L-entrepreneurs invest residual assets in foreign bubbly assets instead. That upturn of the equilibrium interest rate has the same two effects on the economic growth rate as in a nobubble economy. Combining Equations (20) and (22), the interest rates when the economic growth rates in both cases become equal are (see Appendix D):

$$
r_{a}^{w}=\alpha^{H} \frac{(1-\beta) \theta+p \beta}{1-\beta+p \beta} \text { and } r_{b}^{w}=\frac{\alpha^{H} \theta}{\beta(1-p)} \text {, if } \underline{\theta} \leq \theta<\beta(1-p) \text {, }
$$

where $r_{a}^{w}$ is the equilibrium interest rate in the internal bubble economy and $r_{b}^{w}$ corresponds to the interest rate where the two effects cancel each other out. The magnitude relationship between them is determined by the level of financial friction, and the branch point is

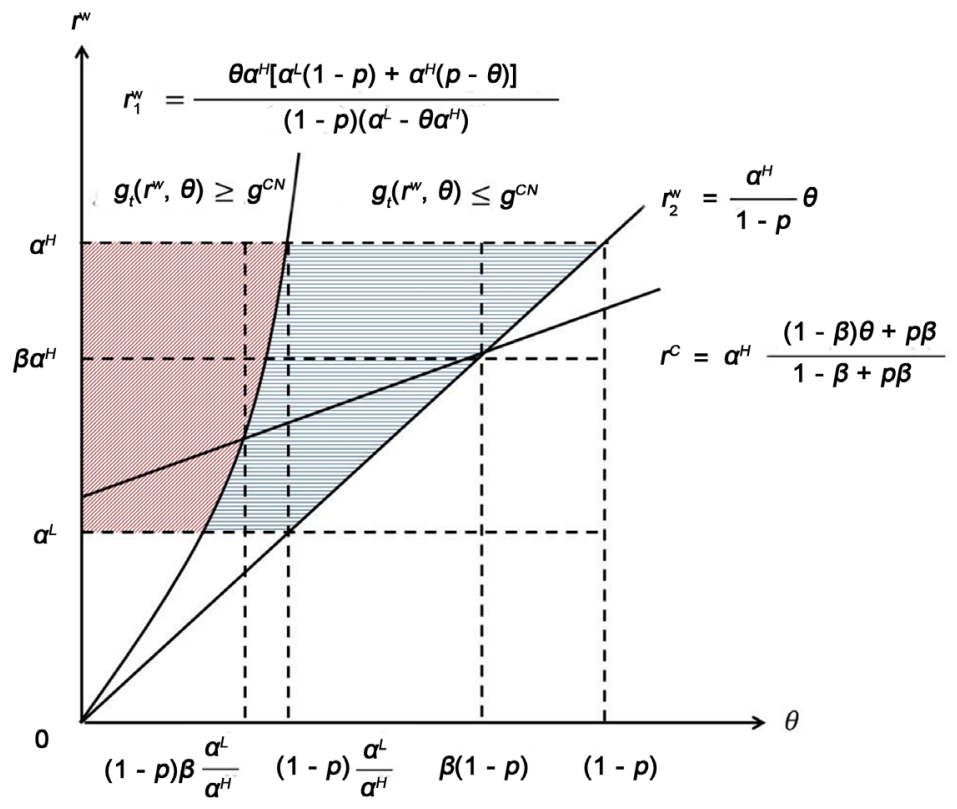

Figure 4. The relationship between economic growth rate and foreign investment return in small countries. 


$$
\theta^{*}=\frac{p \beta^{2}(1-p)}{(1-p)(\beta-1)^{2}+p} .
$$

As a result, we have the following theorem.

Theorem 4. Foreign asset bubbles enhance the economic growth rate in small countries with high financial friction much more than internal asset bubbles do: $g_{t}\left(r^{w}\right)>g_{t}^{C}$, if $r^{w}>r_{a}^{w}$.

Theorem 4 shows that financial globalization brings an additional investment income to the entrepreneur and he invests the income in internal projects in the future which stimulates capital accumulation in the country $\left(\underline{\theta} \leq \theta<\theta^{*}\right)$. This gives a theoretical grounding to the fact that countries with high financial friction experienced high economic growth rates before the collapse of Lehman Brothers.

\subsection{Effects of Bubbles Bursting}

In this subsection, we analyze the effects of bubbles bursting in a large foreign country. The value of foreign bubbly assets becomes zero after the bubble bursts. Combining Equation (20) and the condition on $k_{t}$, the economic growth rate in a small country is then

$$
g_{t}^{A}=\beta \alpha^{H}\left(\frac{r^{w} p}{r^{w}-\theta \alpha^{H}}\right),
$$

where $A$ is an index indicating an economy after the bubble bursts. As is clear from this equation, the effect of bubbles bursting in a large foreign country is much larger than it is in countries with high financial friction $\left(\partial g_{t}^{A} / \partial \theta>0\right)$. In addition to that, as the the foreign investment return increases, the greater is the influence $\left(\partial g_{t}^{A} / \partial r^{w}<0\right)$. That is, countries with high financial friction invest much more in foreign bubbly assets than countries with low financial friction do. As a result, they gain much higher investment return from foreign bubbly assets before the bubble bursts. On the other hand, they are subject to much a greater negative impact after the bubble bursts. This conclusion implies that financial globalization causes fluctuations in the world economy, and it is consistent with the experience of many countries before and after the fall of Lehman Brothers.

\section{Concluding Remarks}

We have analyzed the characteristics of asset bubbles in a global economy. We introduced foreign bubbly assets into the model of Hirano and Yanagawa [7] and then extended the model to examine the features of asset bubbles in an open economy.

This paper has made several contributions to the literature. First, we have shown that financial globalization relaxes the existence conditions for asset bubbles. Small countries with financial friction have some residual assets and invest them in foreign bubbly assets. As a result, foreign asset bubbles are introduced into the small countries. This means that more countries have the potential to experience asset bubbles in a global economy. This result is consistent with observed facts before and after the collapse of Lehman Brothers.

Second, we showed that financial globalization enhances the economic growth rate in 
small countries with high financial friction before the bursting of a foreign asset bubble. They are also subject to a greater negative impact after that. That is because countries with high financial friction invest much more in foreign bubbly assets than countries with advanced financial markets do. As a result, they gain a much greater investment return from foreign bubbly assets before the bubble bursts, but they lose much more afterwards.

We have also shown that the effect of asset bubbles in a global economy becomes larger than it is in closed economy. That is because the investment return from foreign bubbly assets is higher than it is from internal bubbly assets. This conclusion implies that financial globalization may cause large movements in the world economy. These results are different from those of Olivier [12] who concluded that asset bubbles do not affect the long-run growth rate in a small open economy.

This paper leaves some promising areas for a future research. The introduction of capital accumulation would enable the study of a negative growth rate after a bubble bursts. Second, the prior distribution of risk is important for the construction of an asset portfolio. A very interesting topic for analysis would be the effects of a change in risk distribution on economic growth. I look forward to continuing my research in this field.

\section{Acknowledgements}

My heartfelt appreciation goes to attendees for a research seminar held in Development Bank of Japan Inc., whose comments and suggestions were of inestimable value for my study.

\section{References}

[1] Samuelson, P. (1958) An Exact Consumption-Loan Model of Interest with or without the Social Contrivance of Money. The Journal of Political Economy, 66, 467-482.

http://dx.doi.org/10.1086/258100

[2] Tirole, J. (1985) Asset Bubbles and Overlapping Generations. Econometrica, 53, 1499-1528. http://dx.doi.org/10.2307/1913232

[3] Caballero, R. and Krishnamurthy, A. (2006) Bubbles and Capital Flow Volatility: Causes and Risk Management. Journal of Monetary Economics, 53, 35-53.

http://dx.doi.org/10.1016/j.jmoneco.2005.10.005

[4] Kocherlakota, N. (2009) Bursting Bubbles: Consequences and Cures. mimeo.

[5] Martin, A. and Ventura, J. (2012) Economic Growth with Bubbles. The American Economic Review, 102, 3033-3058. http://dx.doi.org/10.1257/aer.102.6.3033

[6] Farhi, E. and Tirole, J. (2012) Bubbly Liquidity. The Review of Economic Studies, 79, 678706. http://dx.doi.org/10.1093/restud/rdr039

[7] Hirano, T. and Yanagawa, N. (2013) Asset Bubbles, Endogenous Growth, and Financial Frictions. Mimeo.

[8] Hirano, T., Inaba, M. and Yanagawa, N. (2015) Asset Bubbles and Bailouts. Journal of Monetary Economics, 76, S71-S89. http://dx.doi.org/10.1016/j.jmoneco.2015.09.008

[9] Tirole, J. (2005) The Theory of Corporate Finance. Princeton University Press, Princeton.

[10] Brunnermeier, M., et al. (2009) The Fundamental Principles of Financial Regulation. Ge- 
neva Reports on the World Economy 11.

[11] The World Bank (2010) World Development Indicators.

[12] Olivier, J. (2000) Growth-Enhancing Bubbles. International Economic Review, 41, 133-152. http://dx.doi.org/10.1111/1468-2354.00058 


\section{Appendix A}

To clarify the meaning of financial friction, we provide a micro-foundation for $\theta$. We define the revenue that an entrepreneur gains by working conscientiously as $R$ ( $\equiv \alpha^{i} z_{t}^{i}+r^{w} w_{t}^{i}$ ), and the lucre he gains by embezzling company's funds as $L$. Since banking corporations (lenders) would like to avoid the entrepreneur (borrower) embezzling funds, the borrowing condition should satisfy $L \leq R-r^{w} b_{t}^{i}$. From an elementary calculation, this inequality can be rewritten as

$$
r^{w} b_{t}^{i} \leq(1-L / R) R
$$

Here, we can redefine the parameter $\theta$ as $(1-L / R)$. The degree of $\theta$ depends on the amount of $L$. Thus, the degree of financial friction depends on the level of monitoring technology in banking corporations. In a country with an undeveloped financial sector, the entrepreneur finds it easy to embezzle company's funds, and so banking corporations limit the amount of lending. To simplify the discussion, the ratio of $L / R$ is assumed to be constant and exogenously given in this paper.

\section{Appendix B}

\section{Necessary condition}

If an economy has a stable internal bubble equilibrium, the relative size of foreign bubbly assets is required to be constant $\left(k_{t+1}^{C} / k_{t}^{C}=1\right)$. When we define the relative size of foreign bubbly assets and the growth rate of the aggregate wealth in a closed economy, respectively, as $k_{t}^{C} \equiv X_{t} / \beta\left(Y_{t}^{C}+r_{t-1}^{C} X_{t-1}\right)$, and $g_{t}^{C} \equiv\left(Y_{t+1}^{C}+r_{t}^{C} X_{t}\right) /\left(Y_{t}^{C}+r_{t-1}^{C} X_{t-1}\right)$, we have

$$
\frac{k_{t+1}^{C}}{k_{t}^{C}}=\frac{X_{t+1}}{X_{t}} \frac{\beta\left(Y_{t}^{C}+r_{t-1}^{C} X_{t-1}\right)}{\beta\left(Y_{t+1}^{C}+r_{t}^{C} X_{t}\right)}=\frac{r_{t}^{C}}{g_{t}^{C}}=1 .
$$

As a result, $r_{t}^{C}=g_{t}^{C}$ is a necessary condition to have a stable internal bubble equilibrium.

2. Sufficient condition

The transversality condition in an internal bubble equilibrium is

$$
\liminf _{t \rightarrow \infty} \beta^{t} \frac{1}{c_{t}^{C i}} x_{t}^{i}=0 .
$$

At date $t+1$, this equation can be rewriten as follows,

$$
\begin{gathered}
\lim _{t \rightarrow \infty} \inf \beta^{t+1} \frac{1}{c_{t+1}^{C i}} x_{t+1}^{i}\left(\frac{1}{\beta^{t}} c_{t}^{C i} \frac{1}{x_{t}^{i}}\right)\left(\beta^{t} \frac{1}{c_{t}^{C i}} x_{t}^{i}\right)=0, \\
\lim _{t \rightarrow \infty} \inf \beta^{t} \frac{c_{t}^{C i}}{c_{t+1}^{C i}} \frac{x_{t+1}^{i}}{x_{t}^{i}}\left(\beta^{t} \frac{1}{c_{t}^{C i}} x_{t}^{i}\right)=0 .
\end{gathered}
$$

Considering that an entrepreneur with the log-linear utility function (1) consumes a fraction $1-\beta$ of his net worth every period, Equation (34) can also be expressed as

$$
\lim _{t \rightarrow \infty} \inf \beta \frac{(1-\beta) e_{t}^{C i}}{(1-\beta) e_{t+1}^{C i}} \frac{x_{t+1}^{i}}{x_{t}^{i}}\left(\beta^{t} \frac{1}{c_{t}^{C i}} x_{t}^{i}\right)=0,
$$




$$
\lim _{t \rightarrow \infty} \inf \frac{r_{t}^{C}}{g_{t}^{C}}\left(\beta^{t} \frac{1}{c_{t}^{C i}} x_{t}^{i}\right)=0 .
$$

As a result, $r_{t}^{C}=g_{t}^{C}$ is a sufficient condition to have a stable internal bubble equilibrium.

(Q.E.D)

\section{Appendix C}

We first consider the effects of financial globalization on the economic growth rate in countries with high financial friction, and then the case of low financial friction is analyzed. Countries with low financial friction realize the same economic growth rate as a perfect financial market, because the borrowing constraint does not bite. However, countries with high financial friction do not realize such a high economic growth rate. Thus, we consider following two cases.

1. Countries with high financial friction $\left(0 \leq \theta<(1-p) \alpha^{L} / \alpha^{H}\right)$

The foreign investment return that equalizes the economic growth rate in a foreign bubble equilibrium with that in a no-bubble equilibrium is derived as the solution of following equation:

$$
\begin{aligned}
& \beta r^{w}+\beta p\left(\alpha^{H}-r^{w}\right) \frac{r^{w}}{r^{w}-\theta \alpha^{H}}=\beta \alpha^{L}+\beta p\left(\alpha^{H}-\alpha^{L}\right) \frac{\alpha^{L}}{\alpha^{L}-\theta \alpha^{H}} \\
& \left(r^{w}\right)^{2}(1-p)\left(\alpha^{L}-\theta \alpha^{H}\right)-r^{w}\left[\theta\left(r^{w}\right)^{2}(p-\theta)+(1-p)\left(\alpha^{L}\right)^{2}\right] \\
& +\theta \alpha^{H} \alpha^{L}\left[\alpha^{L}(1-p)+\alpha^{H}(p-\theta)\right]=0
\end{aligned}
$$

The solutions of the above quadratic function satisfy the conditions

$$
\begin{gathered}
r_{1}^{w}+r_{2}^{w}=\frac{\theta\left(\alpha^{H}\right)^{2}(p-\theta)+(1-p)\left(\alpha^{L}\right)^{2}}{(1-p)\left(\alpha^{L}-\theta \alpha^{H}\right)}, \\
r_{1}^{w} r_{2}^{w}=\frac{\theta \alpha^{H} \alpha^{L}\left[\alpha^{L}(1-p)+\alpha^{H}(p-\theta)\right]}{(1-p)\left(\alpha^{L}-\theta \alpha^{H}\right)} .
\end{gathered}
$$

It is clear that the economic growth rate in both countries becomes equal when the investment interest rate becomes equal to internal equilibrium rate. Thus, $r_{1}^{w}=\alpha^{L}$ is one solution. The other solution $r_{2}^{w}$ is

$$
r_{2}^{w}=\frac{\theta \alpha^{H}\left[\alpha^{L}(1-p)+\alpha^{H}(p-\theta)\right]}{(1-p)\left(\alpha^{L}-\theta \alpha^{H}\right)} .
$$

Considering the shape of a quadratic function, we have

$$
g_{t}\left(r^{w}\right)>g_{t}^{C N}, \text { if } r^{w}>\operatorname{Max}\left[r_{1}^{w}, r_{2}^{w}\right] \text {. }
$$

2. Countries with low financial friction $\left((1-p) \alpha^{L} / \alpha^{H} \leq \theta<1-p\right)$

The foreign investment return that equalizes the economic growth rate in foreign bubble equilibrium with that in an internal bubble equilibrium is derived from the following equation: 


$$
\beta r^{w}+\beta p\left(\alpha^{H}-r^{w}\right) \frac{r^{w}}{r^{w}-\theta \alpha^{H}}=\beta \alpha^{H}
$$

This has the solution

$$
r_{3}^{w}=\frac{\alpha^{H}}{1-p} \theta
$$

In this case, it is clear that

$$
g_{t}\left(r^{w}\right)<g_{t}^{C N} \text {, if } r^{w}>r_{3}^{w}
$$

(Q.E.D)

\section{Appendix D}

The foreign investment return that equalizes the economic growth rate in a foreign bubble equilibrium with that in an internal bubble equilibrium is derived as the solution of the following equation:

$$
\beta r^{w}+\beta p\left(\alpha^{H}-r^{w}\right) \frac{r^{w}}{r^{w}-\theta \alpha^{H}}=\alpha^{H} \frac{(1-\beta) \theta+p \beta}{1-\beta+p \beta} .
$$

This equation can be rewritten as follows:

$$
\beta(1-p)\left(r^{w}\right)^{2}+r^{w} \alpha^{H}(\beta p-\theta \beta-A)+\left(\alpha^{H}\right)^{2} \theta A=0,
$$

where $A \equiv[(1-\beta) \theta+p \beta] /[1-\beta+p \beta]$, and $\theta$ satisfies the existence condition for internal bubbly assets $(\underline{\theta} \leq \theta<\beta(1-p))$. To derive the solution of the equation, we opt for a similar approach to that used in the case above. The solutions of Equation (36) satisfy the following conditions:

$$
\begin{gathered}
r_{a}^{w}+r_{b}^{w}=-\frac{\alpha^{H}(\beta p-\theta \beta-A)}{\beta(1-p)}, \\
r_{a}^{w} r_{b}^{w}=\frac{\left(\alpha^{H}\right)^{2} \theta A}{\beta(1-p)} .
\end{gathered}
$$

It is clear that the economic growth rate in both countries becomes equal when the investment interest rate becomes equal to the internal equilibrium rate. Thus, $r_{a}^{w}=\alpha^{H} A$ is one of the solutions. The other solution $r_{b}^{w}$ is

$$
r_{b}^{w}=\frac{\alpha^{H} \theta}{\beta(1-p)} .
$$

Considering the shape of a quadratic function, we have

$$
g_{t}\left(r^{w}\right)>g_{t}^{C}, \text { if } r^{w}>\operatorname{Max}\left[r_{a}^{w}, r_{b}^{w}\right] \text {. }
$$

The magnitude relationship of these solutions depends on the level of financial friction. The branch point in the level of financial friction is

$$
\theta^{*}=\frac{p \beta^{2}(1-p)}{(1-p)(\beta-1)^{2}+p}
$$


where $r_{b}^{w}<r_{a}^{w}$ if $\theta<\theta^{*}$. Thus, in countries with high financial friction, where $\underline{\theta}<\theta<\theta^{*}$, the introduction of foreign bubbly assets $\left(r^{w}>r_{a}^{w}\right)$ enhances the economic growth rate $\left(g_{t}\left(r^{w}\right)>g_{t}^{C}\right)$.

(Q.E.D)

Submit or recommend next manuscript to SCIRP and we will provide best service for you:

Accepting pre-submission inquiries through Email, Facebook, LinkedIn, Twitter, etc. A wide selection of journals (inclusive of 9 subjects, more than 200 journals)

Providing 24-hour high-quality service

User-friendly online submission system

Fair and swift peer-review system

Efficient typesetting and proofreading procedure

Display of the result of downloads and visits, as well as the number of cited articles Maximum dissemination of your research work

Submit your manuscript at: http://papersubmission.scirp.org/

Or contact tel@scirp.org 